This is an Accepted Manuscript of an article published by Taylor \& Francis in Information, Communication \& Society on 07/06/2018, available online:

https://www.tandfonline.com/doi/full/10.1080/1369118X.2018.1476574 


\section{Study trip as means of expanded learning}

E. Liu, S. Carta \& E. Sopeoglou

To cite this article: E. Liu, S. Carta \& E. Sopeoglou (2018) Study trip as means of expanded learning, Information, Communication \& Society, 21:9, 1293-1304

Study trip as means of expanded learning

E. Liu, S. Carta and E. Sopeoglou

School of Creative Arts, University of Hertfordshire, Hatfield, UK

ARTICLE HISTORY

Received 31 January 2018

Accepted 9 May 2018

KEYWORDS

Word; study trips; public

space; multi culture; field

work; studio teaching

\section{ABSTRACT}

This article explores the study trip as an interconnected activity of work and play, constituting an extended means of teaching design studio in spatial design related disciplines. This study analyses the case of a cohort of about 200 students involved in a joint project in three cities, Athens, Tokyo and London, where groups were challenged with a common project brief. The students conducted empirical studies of the cities through play and enjoyment. The case study provides evidence of the benefits and issues emerging in this particular teaching and learning method of project-based and field work research in spatial design.

\section{Introduction}

Conventional spatial design education involves predominantly studio-based teaching, with occasional field work and study trips to reinforce the knowledge and understanding of the subject. This article focuses on using field work and study trips as a pedagogical tool to explore the learning process through play and enjoyment; and discusses how the findings may, in return, influence studio teaching.

In this paper, the study addresses the research question of: (i) to what extent does the study trip connected to an on-site activity add to the students' experience and learning in the spatial design education? Secondary questions are: (ii) what are the benefits and issues related to joint projects in three different countries, including a diversity of education systems, cultural and social constructs, and architectural backgrounds? And (iii) how did students manage their own learning within multi-cultural groups working together on the same given project brief?

These research questions enabled us to, on the one hand, initially design and guide the student projects through, to completion. On the other hand, they allowed us to reflect and evaluate on the projects' outcomes and our experience using them as learning and teaching tools. The project covered 3 cities, involved 3 university programmes with over 200 students and staff. It took many months of planning that condensed into week-long visits and a few 
days of field work. We were faced with logistic and practical challenges, but overall, both tutors and students benefitted from the study trip experience and live project element of the study.

In this paper, we will provide information on our course's curriculum set-up, we will elaborate on the three projects' agendas, explain the methodology applied to this particular research project, provide key literature that underpins the type of work we were involved in, discuss the main research outcomes via three key research questions, and finally, offer an evaluation of the projects' outcomes with regards to pedagogy and teaching methods, while also offering a few further questions we were able to draw from our experience.

\section{Curriculum}

The curriculum of Interior Architecture and Design programme in the University of Hertfordshire (UH) consists of 11 modules, of which 10 modules include scheduled external learning activities such as fieldwork, external visits and work-based learning in the module activities. These external learning activities range from 5 to 30 hours per module. The total hours for the external learning activities are 31 hours, equivalent to $2.58 \%$ of 1200 total study hours in year one; 56 hours or $4.67 \%$ in year two; and 30 hours or $2.5 \%$ in year three. In other words, a full-time student will spend 117 hours, which is $3.25 \%$ of their total study hours, over the three-year period of the degree course in conducting fieldwork, external visits, etc. Fieldwork and external visit as a pedagogy is particularly important to modules that require up-to-date knowledge of the industry and the market, such as the Advanced Technology module in year two. The module is 30 credits with 300 total study hours, of which 30 hours or $10 \%$ of the total study hour is allocated to scheduled external learning activities. The fieldwork includes physical exploration of the interior and exterior of public spaces: research into the environmental conditions of sites such as light, acoustic, spatial arrangement, surface materials, structure, technologies, etc. Most importantly, analyse what are the design thinking and strategies to approach such environmental conditions? And how these design strategies impact on users' experience? Through on-site observation and data collection, analyses are conducted on how people used the spaces? How they move around and within spaces? The knowledge of the relationship between building spaces and users, and the skills to acquire such knowledge through fieldworks and study trips are used to inform studio practice. The curriculum links all skills-based modules, such as the Advanced Technology module, with design-based modules, such as Design Studio modules. Hence, the students are able to translate the findings on site into their studio practice. The pedagogy of fieldwork-led learning creates a fun environment for the students to conduct primary research. It also encouraged students to develop an open mind-set to allow new information to flow through freely, through engaging their studies with their surrounding environment.

\section{The project}

The Project was named Mapping the Public Space. It involves mapping a series of privatelyowned public spaces (POPS) in London, Tokyo and Athens. The project focused on interior and semi enclosed spaces, which were used by the public, enclosed by walls, fences, and any physical or virtual elements that made the spaces 'interior'. The project aimed to discover and represent elements of the public space that were hidden to the naked eye or on the basic maps. Different mapping techniques were used to unveil aspects such as the 
real use of space by people, spontaneous appropriation of spaces, discrepancies between the orderly designed spaces by the authorities and the real space created by the public, spatial modification over time and uses, people's choices and movement in spaces, etc. The project was organised by the Interior Architecture and Design tutor team in the UH, UK, and collaborated with the tutor teams of similar programmes in ICS College of Arts, Tokyo, Japan and Technological Educational Institute of Athens, Greece. On March 2016, a cohort of about 100 students from the UH travelled to Tokyo and Athens. They were joined by peers from these schools and formed teams of five to six student per group. UK students who were unable to travel abroad, participated in the same project in London. Given the vast scale of the cities, student groups were instructed to focus on certain locations of each city. The sites were chosen from recommendations by local peers. Southbank was chosen for the London team for its art culture and anarchist colonisation of the under-croft spaces, especially around the Southbank Centre. For the Tokyo team, Omotesanto was recommended for being the most socially and commercially diverse area in Tokyo, where high-end super-brand retails are juxtaposed with alternate youth cultures such as Cosplay, Punk and Lolita, as well as the traditional Meiji Shrine in Harajuku district. In Athens, the Plaka area was chosen as the heart of the city with easy access to the Acropolis and ancient temples, an area consisted of both commercial and tourist activities in the public spaces, as well as the residential area of the Anafiotika neighbourhood.

\section{Methodology}

The various sites in the three cities were selected on the basis of contention as a public space, but also their level of re-appropriation. Gordon Cullen, an urban designer who formed the planning principles for London Southbank using the Townscape theory noted that 'Townscape' is the art of giving visual coherence and organisation to the jumble of buildings, streets and spaces that make up the urban environment' (Cullen, 1961). Cureton (2016) argued that 'Townscape is the representation of succession and movement in space and through such work acts as an agent to generate new modes of work and play'. Students conducting fieldwork were faced, on the one hand, with contemporary forms of play and re-appropriation, but also situating themselves in architectural spaces devised specifically for visual excitement, juxtaposition and with playful aesthetic narratives. In the design of areas which provide 'emotional impact' Gordon Cullen's urban design method titled 'serial vision' has proven influential. The method would involve a walked route mapped in plan, paired with referenced perspective drawings showing the walk progression or seriality (Cullen, 1961, pp. 17-18). Visual and emotional impact is created by designing transitory routes which provide existing and emerging views creating stimulating mixes. Furthermore, the book 'The Concise Townscape' contains static images and text, mixed with studied perspectives relating to a plan (Cullen, 1961). Applying Cullen's serial vision method, students conducted a series of perspectives on a pre-prescribed route recording playful narratives and activities of users and their re-appropriation of space. For example, the Southbank Under-croft is known as a skateboarding icon, in which skateboarders, bmx-ers and free-runners created new spaces through playful dialogue with the brutalist architecture; thus, via the act of skating, architecture is in an internal and external relationship with humans (Borden, 2001, p. 135). These tactics can arguably be recorded using Cullen's approach of serial vision. In combination, they are showing how the performance of architectural spaces and the ability of these designs to work, work with or against inhabitants. The Southbank fieldwork evidenced the ability of architectural space to 
be appropriated for tactical play through urban sports or restrict this dialogue through generalisation and characterless programming of the urban space. This fieldwork was, thus, critical for students' experience in development methods of representing space and observational learning during their spatial design education.

\section{Research enquiries}

Through the Mapping the Public Space project, we identified three research questions which we explored through primary data collection and analysis. They were as below:

- Question 1: To what extent does the study trip connected to an on-site activity add to the students' experience and learning in their spatial design education?

To understand how the students may learn through fieldwork and on-site activities, the tutor team looked for precedents and established theories that could inspire our methodology for the project. We identified key literature which focuses on rethinking public space in cities through play-related themes. Walter Benjamin's Flâneur (1997) provided the unique gaze of a stroller, someone who is strolling through the crowds in a city; s/he was an urban explorer with a poetic endearment venturing into places, and especially public spaces. The book suggested a mental process of digesting information gathered through objective observation and processed through artistic imagination. Guy Debord's Dérive (1956) defined drifting through an urban space as an experimental behaviour, or an unplanned journey with the participants consciously ignoring their everyday experience, and allowing their bodies to walk to whatever urban artefact, landscape and structures that attract their eyes, and exposed themselves to whatever they may encounter there. A derive could be done solo or within small groups. If drifting among a small group, participants may arrive at the same level of awareness and share their findings in order to draw objective conclusions. The Dérive theory probed the tutor teams to ask critical questions on how the formation of the groups may have impacted on their 'objective conclusions' at the end of the project. Did their cultural, age and ethnic group make any differences to their experience? How important was it for local students within the groups to abandon their prerequisite experience? And for visitor students to ignore their expectation of the cities while drifting took place? Johan Huizinga's Homo Ludens (1944) concept allowed us to justify engaging 'play' as a means of learning about cultures, places, spaces, and pedagogy. According to Huizinga, 'play' is a cultural phenomenon, which has an inseparable bond with art, poetry, philosophy, language, even law and war. In our case for architecture, spaces, and places, exteriors and interiors play indicated an innate ability to acquire new knowledge; it gave freedom to imagination and meanings to matters, yet it created order at the same time. Using play as a methodology for the project helped us to establish a harmonic balance between work and leisure. As all games come with guidelines and rules, gamers respect those rules while engaged with them. We set up parameters and boundaries for the project, participating students were expected to follow them, as well as challenge them. And most importantly, students would acquire new knowledge and skills, while having fun in the process; in other words, they would learn without consciously knowing they are studying. Lefebvre (1991) suggests to read deeper into the social meaning and constructs of spaces. In 'The social production of space', he argued that urban spaces are a complex social product. Urban space is more than just an accommodation of people and objects. Rather than studying only its physical quality and features, Lefebvre stipulates we should look into the process of producing urban space. Space is used as a tool of thoughts and actions, hence, it can be an expression of civic liberty; but it can also be a means of 
control and power. In 'Skateboarding, Space and the City' (2001) lan Borden, based on Lefebvre's theory, claimed that skateboarding as a practice reclaimed and remade urban space. Skateboarding can be a metaphor of how individuals can appropriate public spaces and the build environment to accommodate their own needs and purposes. And while this urban practice was anarchist it was also creatively political, rebellious and presented an organised chaos, and an alternative way of doing things. This leads us to think that if every society or city produces its own social space, where would their actions and thoughts lead to? Would it be a discourse of a constant negotiation between the authorities and the people? Michel de Certeau (2011) in 'The Practice of Everyday Life' described the authorities or institutions as 'producers', and individuals as 'consumers'. On the one hand, city planning which was generated by the 'strategies' of government/ institutions/ authorities produced a unified image of a city. On the other hand, in everyday practice, individuals use 'tactics' to walk, move, dwell, act and consume city spaces which never fully followed the plans of the authorities. Certeau argued that everyday life was a process of negotiating between the prescribed guidelines and rules by authorities and the opportunities of challenging these rules by individuals. In turn, we found that people would take shortcuts through urban spaces even though there were pre-existing rigid paths and streets; businesses would negotiate with local authorities to extend their territories onto pavements; street vendors, performers, skateboarders and other users may seize momentarily the opportunity to colonise street corners, parks and squares with or without consensus from the authorities. These aspects of how everyday life unfolds in the production of social space were the main interest of our project. The common thread of the above literatures demonstrates that users engaged with public space in cities has political potential, that citizens could hack into the imposed architectural or urban planning programmes of technocrats, politicians and architects. These literatures provided the team with academic theories to guide the projects' direction; and helped narrow down the topic of interest whilst conducting primary data collection.

- Question 2: what are the benefits and issues related to joint educational projects in three different countries, involving a diversity of education systems, cultural and social constructs, and architectural backgrounds?

In this aspect, the studio experience of interior architecture and design students has been expanded to the real scenario of three cities: London, Athens and Tokyo, as a collaboration among three academic institutions: the UH - School of Creative Arts - Interior Architecture and Design Programme, the Technological Educational Institute of Athens - Faculty of Fine Arts and Design - Department of Interior Architecture, Decoration and Design, and the ICS College of Arts in Tokyo. The project consisted in the mapping (drawing of the most significant signs in a map) of a series of POPS in these three cities. The project ran for a week in February 2016, in conjunction with the study trip of the UH students. The project focused on interior spaces used by public and enclosed by walls, fences, or other elements (virtual or physical) that make the space interior. The choice of working on the notion of public and private spaces, and the tension between them is an increasingly urgent question to be defined within the contemporary architecture debates at a global scale (Acconci, 1990; DiSalvo, 2009; Kayden, 2000; Van Melik, Van Aalst, \& Van Weesep, 2009). The project aimed to discover and represent elements of the public space that are hidden to the naked eye or in the basic maps (e.g., in tourist maps). Mapping was chosen as the main on-site and off-site technique to gather observational data and to provide a consistent informational device (Schoonderbeek, 2015; Schoonderbeek \& Havik, 2014) to the three cohorts of 
students. The substantial importance of physical mapping (in other disciplines called fieldwork) is illustrated by many scholars, predominantly within the realm of geography (e.g., Fuller, Rawlinson, \& Bevan, 2000, Kent, Gilbertson, \& Hunt, 1997). Different mapping techniques have been employed to unveil epitomising aspects of the social life of cities, including real use of space by people, spontaneous appropriation of space, discrepancies between the orderly space and the real space, spatial modification over time and use, and people's choices and movement in space. Within each city, the areas of study have been chosen by each group of students. Special attention has been given to what elements, factors, and conditions make the chosen areas 'public' (physical characteristics of the built environment, ownership, historical, symbolical, or referential aspects of the areas). In the indoor studio the cultural aspect of society is mutually shared among academics, students, and the final users of the design. The outdoor studio broke this implicit paradigm, exposing the students to different cultures, and hence a new understanding of the city and the norms that regulate its use. Students mapped the use of the same urban element (e.g., a square) in different cultural contexts, discovering how it is used differently. The interaction with local students (from Athens and Tokyo) provided UH's students with precious insights on the local culture. Within the context of design, students realised that the form and spatial characteristics of the square are not solely responsible for its use nor its success as a public space. The cultural component and the way that people perceive that space are central in the design discourse. The findings supported the students in two different occasions of their learning experience: they provided common and general knowledge about culture, society and cities, as well as informed them on the practical aspects of the day-to-day work in practice. The former aspect can be related to Eklund-Myrskog (1998) argument, where students' experience of learning has been examined in relation to different educational contexts. The latter facet is substantiated by Vescio, Ross, and Adams (2008), who - through the examination of a series of studies - provided evidence on the improvement of student learning in relation to the tutors' involvement in professional learning communities. The experience of the extended design studio has proved beneficial also for the staff involved. As held by many scholars (amongst others, Korthagen, Kessels, Koster, Lagerwerf, \& Wubbels, 2001; Laurillard, 2008, 2012, Voogt et al., 2011) the implementation of a collaborative curriculum is a fundamental part of teaching and learning in the design science disciplines. In our case, the collaboration with other institutions, and the extension of case studies to different urban contexts in other countries represented a significant component in the academics' own research work (Mellar, Oliver, \& Hadjithoma-Garstka, 2009; Mor et al., 2013).

- Question 3: how did students manage their own learning working together in multicultural groups and on the same given project brief?

The study trips offered students and tutors the opportunity to reflect on regular teaching methods. Moreover, it offered students the opportunity and the challenge to manage their own learning. The pedagogical approach of a study trip is very different to the structured learning of regular teaching within modules during the academic year. We felt that the study trips shaped different experiences and the students' learning in three main areas: pedagogy, discipline and professionalism, which we elaborate on in the next sections of this paper.

\section{Pedagogy}

This discussion relates to the way students managed their own learning. The teams were 
organised in groups and were sent off to collect fieldwork data. Fieldwork is a nonhierarchical process, which meant that, for example, mixed groups of 1st year to 3rd year students would work together, and that everyone would then be an equal part of the team. Also, the fact that tutors were not present and not involved during the data collection process meant that the students had to evaluate what data to collect and also were free to devise their own data-collection method (filming, photography, sketching, note-taking, observation, etc.). The fact that no tightly-set brief and deliverables were given, also meant that while some students would struggle to work without the formal 'structure' of taught modules, it also gave students the opportunity to explore ways of self-learning. For students with learning difficulties in a normal classroom, this more 'hands-on' approach to learning can be a liberating and empowering experience. On the other hand, for others, managing individual learning and self-learning could be uncomfortable. Students learned to take initiative, to develop observation skills and invent new ways for representation of data. For example, making maps meant using different media, both analogue (e.g., sketching and making notations) and digital (e.g., device-tracking) to draw them. An inter-institutional collaboration, while not outside of institutional norms, also allowed for the comparison of student profiles coming from different countries and educational backgrounds. At the same time, these one-week-long projects during the study trip were independent from core teaching - for example, the design studio activities - which is what students regularly work on during the academic year. The study trip and fieldwork allowed student groups to work at another scale (i.e., urban scale) and explore different topics (i.e., public space) than what they would usually explore as Interior Architecture students in their studios. Finally, during the one-week-long study trip, learning outcomes could be reached faster, as opposed to a semester-long or year-long module. This experience offered students a different pace than the week-to-week teaching, a different energy emerged from the group, as intense, compact and, at the same time, playful learning was achieved.

\section{Discipline}

This discussion relates to the way students experienced working within multi-cultural groups. In the cases of Tokyo and Athens students worked alongside their peers from other universities, which provided UH's students with precious insights on the local culture. The 'outdoor studio' exposed them to a new understanding of the city and the norms that regulate its use. At the same time, students recognised the particularities of their own discipline. Learning through travelling is a 'signature pedagogy' (Shulman, 2005, p. 52) in architecture. It is characteristic of architecture students at all stages of their formation to embark on travels, to explore the world and to experience first-hand the architecture and ways of living of people in different cultures. In this tradition, during the last two centuries, graduates from Europe and the West would take the 'Grand Tour' and would travel along the Mediterranean. These days, with more convenient means of travel they can experience faraway places before they even graduate. Through travelling, students appreciate the influence of (local) culture in the use and perception of the city. While working in groups, students were also free to discover and develop personal agendas and special interests in their discipline. Through the study trip, becoming an independent researcher was useful practice in developing the brief for their self-initiated projects during the 3rd year of the Bachelor degree course. Thus, the study trip, even though not directly linked, supported design-research, framed a concise research project and supported the design studio. 


\section{Professionalism}

This discussion relates to the way working hands-on and working in teams prepared students for future work in a professional job setting. Group work is uncommon in the UK educational system, unlike, for example, in the Greek educational system, which means that the study trip offered a unique experience for the UK students to spend more time working in groups. Mixed groups enabled students to find common points and middle grounds in design approach and data interpretation. Students were asked to collectively produce maps, working together on a common brief, which meant that naturally some students lead and some followed the team. This very useful experience prepares them for a professional environment in architecture, where they will likely work in larger groups with people they do not know. At the same time, students learned to be accountable in front of their teammates, with no external body or organisation, tutor or 'client' involved. Finally, the study trip was opportunity for social engagement, for students to go out into the world, talk to and observe people, document what people do and how they use public space.

\section{Evaluation}

The project was a collaboration among three institutions located in three cities. The tutor team have observed if the differences in cultural constructs and the education environment in the three institutions had any influence on the way that students worked within a mixed group. The London team was a mixture of British, European and international students; the Tokyo team consisted of Japanese, Taiwanese and British students; while the Athens team was mainly Greek, some with Turkish influence, and some British students. From observation, the ethnic backgrounds of student cohorts did not seem to have a strong impact on the way they interacted with each other. The students tended to regard themselves as global citizens; they accepted each other with respect and blended in without any problem. The students showed an interest in the way that other students from different cultural backgrounds came up with design ideas, and how they approached a design project. They were also interested in the relevant knowledge and skills of their local peers.

Nevertheless, the educational environment of the three cities seemed to play a critical role in the way that students handled themselves and approached the project within the mixed groups. The higher education system in the UK is relatively more profit-driven when comparing to that of Japan and Greece, where students need to pay tuition fees in the UK, unlike their counterparts. We found that UK students were more focused on the project outcomes rather than the process. During the project, students from the UK would start to work on printed maps, floor plans, etc. almost immediately when the project launched. They cared a lot about the quality and quantity of works that their teams were going to produce at the end throughout the process. Generally speaking, students from the UK played an effective role as producers of tangible results. In Japan, the education system showed an established hierarchical system, which everyone respects and follows. The students focused on the user experience in urban space, people's movement and the way people used the spaces. They were also very interested in microscopic details of street and urban space designs, such as pavement texture, street furniture, shop fronts, the relationships among nearby squares and paths, etc. A few mature students with local knowledge also were interested in the hidden history of the urban fabric, and how this defined and contrasted with current urban activities. Students from Tokyo proved to be invaluable members of the teams, who were the effective communicators of ideas and concepts. In Greece, the higher education system is very different from that of the UK and 
Japan. Students are not required to pay a tuition fee. The educational environment there seemed to foster reasoning and debate, and students tended to have a strong political awareness. For example, during the project, students from Athens would spend hours debating and analysing the meaning of 'public'. Although they produced less tangible work as a result, the work they produced was deep in meaning and thought-provoking. They were strong narrators to provide context to the final production of the project. Students from the three cities each contributed to their strengths; and working together in mixed teams created a dynamic professional environment that encouraged everyone to work to the best of their abilities, while at the same time, to explore outside their routines and habits. The feedback from the students was that they found the experience challenging and intense, but they acknowledged they learned a lot from their peers and would welcome similar opportunities in the future.

\section{Conclusion}

The project covered 3 cities, involved 3 university programmes with over 200 students and staff; it took nine months of planning that condensed into two days of field work. The final outputs of the project included presentation posters and documents and a series of maps with specific locational context. A website and videos were also produced (available at https://mappingtheps.wordpress.com/ and at https://youtu.be/_MQpMB_-BAU) a conference presentation, further research papers, etc. Through the project, a new understanding of how culture defines public spaces was developed; students were able to acquire new skills and knowledge through both work and play. We hope to develop a coherent research theme to sustain more international collaborations in the future. The project also proved a valuable experience for the personal and professional development of both staff and students. The challenges would be: the long preparation time and coordination among the three institutions; the high number of students involved with very limited time to conduct the field work, which meant that students needed to learn and to progress independently, as well as to rely on each other as a team. It was also challenging to push the students to break their habit of approaching and handling a design project within such short time frame. Our background research and proposed methodologies were proven to be very helpful in setting up a general guidance and a direction of the project. We would like to conclude by identifying a few questions, which followed from running the study trips, to help understand how to improve and move the study trip methodology further. This is especially important if framed with current emerging teaching and research practices in mind, namely the introduction of live-projects and social-engagement within the architectural education curriculum (Frazer, 2013).

- How can we, instead of another institution involve an external organisation in the study trip set-up, and how would the experience and outcomes be different?

- Can we further encourage students to author their own research projects?

- Can we further give to the study trip more freedom than the normal design project brief?

- If live projects and community-engagement are new and innovative ways to teach architecture, how will this methodology grow within the discipline, and how will it affect the study trip into the future?

- How can the study trip better support the studio project, for example, can we introduce a correlated brief to that in the studio? Can the study trip and studio share common themes, or briefs? 
- Or rather, should the study trip remain independent from core teaching activities, be a non-assessed part of the course curriculum, and offer a place for self-reflection or peer assessment?

- And how then can we manage study trip budgets for tutors' time, visiting lecturers and other resources, if the trip is not part of curriculum teaching, i.e., it is not assessed?

- Can the study trip research become part of the final portfolio submission? With submission formats varying between digital and analogue, is the map the best format to document and represent data?

- Can we introduce external organisations as collaborators to the study trip experience, and what would be their role and formal involvement be?

- How is our role as tutors shifting during the study trip and live project experience, for example, as we move from the educator to the mediator-manager of the students' journey through self-learning?

- How can we generate an impact to society from a study trip research project? Is there one, and how do we document it?

To conclude, we would like to consider how to better frame our study trip approach, within an academic research agenda. Live projects offer opportunity to tie-in with university and our own research. For example, the study trips presented here formed part of a research agenda about the nature and the use of public space. We would like to explore these links and synergies in our future activities.

\section{Disclosure statement}

No potential conflict of interest was reported by the authors.

\section{Notes on contributors}

Erica Liu is a lecturer teaching on BA (Hons) Interior Architecture and Design, and BA (Hons) Architecture in the University of Hertfordshire. She is an interior designer and has a PhD in Cultural Studies [email: e.liu2@herts.ac.uk].

Silvio Carta is a lecturer teaching on BA (Hons) Interior Architecture and Design, and BA (Hons) Architecture in the University of Hertfordshire. He is an architect and critic devoted to the study of architecture [email: s.carta@herts.ac.uk].

Eva Sopeoglou is a lecturer teaching on BA (Hons) Interior Architecture and Design, and BA (Hons) Architecture in the University of Hertfordshire. She is an architect and currently completing her PhD from The Bartlett School of Architecture [email:

eva.sopeoglou@yahoo.com].

\section{References}

Acconci, V. (1990). Public space in a private time. Critical Inquiry, 16(4), 900-918.

Benjamin, W. (1997). Charles Baudelaire: A lyric poet in the era of high capitalism. London: Verso Classics.

Borden, I. (2001). Skateboarding, Space and the City: Architecture and the Body, Bloomsbury Academic, ISBN 1859734936, 9781859734933.

Cullen, G. (1961). The concise townscape. London: Routledge. 
Cureton, P. (2016). Strategies for landscape representation: Digital and analogue techniques. London: Routledge.

de Certeau, M. (2011). The practice of everyday life. Berkeley: University of California Press. DiSalvo, C. (2009). Design and the construction of publics. Design Issues, 25(1), 48-63. Eklund-Myrskog, G. (1998). Students' conceptions of learning in different educational contexts. Higher Education, 35(3), 299-316.

Frazer, M. (Ed.). 2013. Design research in architecture. An overview. Farnham: Ashgate. Fuller, I., Rawlinson, S., \& Bevan, R. (2000). Evaluation of student learning experiences in physical geography fieldwork: Paddling or pedagogy? Journal of Geography in Higher Education, 24(2), 199-215.

Guy, D. (1956). Theory of the Dérive. Les Lèvres Nues \#9 (Paris, November 1956). Reprinted in Internationale Situationniste \#2 (Paris, December 1958). Translated by Ken Knabb.

Huizinga, J. (1944). Homo Ludens. Switzerland: Routledge.

Kayden, J. S. (2000). Privately owned public space: The New York city experience. New York, NY: John Wiley.

Kent, M., Gilbertson, D. D., \& Hunt, C. O. (1997). Fieldwork in geography teaching: A critical review of the literature and approaches. Journal of Geography in Higher Education, 21(3), 313-332.

Korthagen, F. A. J., Kessels, J., Koster, B., Lagerwerf, B., \& Wubbels, T. (2001). Linking practice and theory: The pedagogy of realistic teacher education. New Jersey: Lawrence Erlbaum.

Laurillard, D. (2008). The teacher as action researcher: Using technology to capture pedagogic form. Studies in Higher Education, 33, 139-154.

Laurillard, D. (2012). Teaching as a design science: Building pedagogical patterns for learning and technology. London: Routledge.

Lefebvre, H. (1991). The production of space. Oxford: Blackwell.

Mellar, H., Oliver, M., \& Hadjithoma-Garstka, C. (2009). The role of research in institutional transformation. In T. Mayes, P. Bullen, H. Mellar, \& M. Oliver (Eds.), Transforming higher education through technology-enhanced learning. York: Higher Education Academy. Mor, Y., Luckin, R., Goodyear, P., Grabowski, B., Puntambekar, S., Winters, N., \& Underwood, J.

(2013). SNap! Re-using, sharing and communicating designs and design knowledge using scenarios, narratives and patterns. In Handbook of design in educational technology (pp. 189-200). London: Routledge.

Schoonderbeek, M. G. H. (2015). Place-time discontinuities: Mapping in architectural discourse (Doctoral dissertation). TU Delft, Delft University of Technology.

Schoonderbeek, M., \& Havik, K. (2014). Reading and reacting: From the research of border conditions to experimental methods in architectural and urban design. Nordlit, 0(31), 49-58. Shulman, L. (2005). Signature pedagogies in the professions. Daedalus, 134(3), 52-59. Van Melik, R., Van Aalst, I., \& Van Weesep, J. (2009, August). The private sector and public space in Dutch city centres. Cities (London, England), 26(4), 202-209.

Vescio, V., Ross, D., \& Adams, A. (2008). A review of research on the impact of professional learning communities on teaching practice and student learning. Teaching and Teacher Education, 24(1), 80-91.

Voogt, J., Westbroek, H., Handelzalts, A., Walraven, A., McKenney, S., Pieters, J., \& De Vries, B. (2011). Teacher learning in collaborative curriculum design. Teaching and Teacher Education, 27(8), 1235-1244. 